\title{
Insight into winter haze formation mechanisms based on aerosol hygroscopicity and effective density measurements
}

\author{
Yuanyuan Xie ${ }^{1}$, Xingnan Ye ${ }^{1,2}$, Zhen $\mathrm{Ma}^{1}$, Ye Tao ${ }^{1}$, Ruyu Wang ${ }^{1}$, Ci Zhang ${ }^{1}$, Xin Yang ${ }^{1,2}$, Jianmin Chen ${ }^{1,2}$, and \\ Hong Chen ${ }^{1}$ \\ ${ }^{1}$ Shanghai Key Laboratory of Atmospheric Particle Pollution and Prevention (LAP ${ }^{3}$ ), \\ Department of Environmental Science and Engineering, Fudan University, Shanghai 200433, China \\ ${ }^{2}$ Institute of Atmospheric Sciences, Fudan University, Shanghai 200433, China \\ Correspondence to: Xingnan Ye (yexingnan@fudan.edu.cn) and Jianmin Chen (jmchen@fudan.edu.cn)
}

Received: 9 January 2017 - Discussion started: 16 February 2017

Revised: 17 April 2017 - Accepted: 7 May 2017 - Published: 16 June 2017

\begin{abstract}
We characterize a representative particulate matter (PM) episode that occurred in Shanghai during winter 2014. Particle size distribution, hygroscopicity, effective density, and single particle mass spectrometry were determined online, along with offline analysis of water-soluble inorganic ions. The mass ratio of SNA / $\mathrm{PM}_{1.0}$ (sulfate, nitrate, and ammonium) fluctuated slightly around 0.28 , suggesting that both secondary inorganic compounds and carbonaceous aerosols contributed substantially to the haze formation, regardless of pollution level. Nitrate was the most abundant ionic species during hazy periods, indicating that $\mathrm{NO}_{x}$ contributed more to haze formation in Shanghai than did $\mathrm{SO}_{2}$. During the representative PM episode, the calculated PM was always consistent with the measured $\mathrm{PM}_{1.0}$, indicating that the enhanced pollution level was attributable to the elevated number of larger particles. The number fraction of the near-hydrophobic group increased as the PM episode developed, indicating the accumulation of local emissions. Three "banana-shaped" particle evolutions were consistent with the rapid increase of $\mathrm{PM}_{1.0}$ mass loading, indicating that the rapid size growth by the condensation of condensable materials was responsible for the severe haze formation. Both hygroscopicity and effective density of the particles increased considerably with growing particle size during the bananashaped evolutions, indicating that the secondary transformation of $\mathrm{NO}_{x}$ and $\mathrm{SO}_{2}$ was one of the most important contributors to the particle growth. Our results suggest that the accumulation of gas-phase and particulate pollutants under stagnant meteorological conditions and subsequent rapid particle
\end{abstract}

growth by secondary processes were primarily responsible for the haze pollution in Shanghai during wintertime.

\section{Introduction}

Atmospheric aerosol has significant influences on radiation balance and climate forcing of the atmosphere (Wang et al., 2011, 2014b; G. Wu et al., 2016; IPCC, 2013). Also, atmospheric aerosol has strong impacts on visibility (Yang et al., 2012; Lin et al., 2014; Xiao et al., 2014) and public health (Heal et al., 2012). Recent studies found that short-term exposure to haze pollution could cause airway inflammation and aggravate respiratory symptoms in chronic obstructive pulmonary disease patients (S. Wu et al., 2016; Guan et al., 2016).

With the huge achievements in economic development and rapid urbanization over the past 30 years, particulate pollution has become a major environmental concern in China. The most severe haze event that occurred in the first quarter of 2013 spread over 1.6 million $\mathrm{km}^{2}$ (Wang et al., 2014). This event motivated the release of the Action Plan on Prevention and Control of Air Pollution with the goal of reducing $\mathrm{PM}_{2.5}$ (particulate matter smaller than $2.5 \mu \mathrm{m}$ in aerodynamic diameter) concentration by 15-25\% (2012) by 2017 in three major city clusters (http://english.mep.gov.cn/News_service/ infocus/201309/t20130924_260707.htm). In order to reduce the $\mathrm{PM}_{2.5}$ concentration, extensive studies have been conducted to investigate the sources and formation mechanisms of haze pollution in recent years (Ye et al., 2011; Sun et al., 
2016; Qiao et al., 2016; Hu et al., 2016; Li et al., 2016; Guo et al., 2014, 2013; Zheng et al., 2015; Wang et al., 2016; Peng et al., 2016). However, the haze formation mechanisms and source appointment of fine particles remain uncertain.

Guo et al. (2013) summarized historical reports from 2000 to 2008 in Beijing and found that the origins of urban fine particles varied in different seasons: the contribution of primary emissions is comparable to that of secondary formation during winter heating periods whereas secondarily produced aerosols dominate the fine PM sources in other seasons. As an important type of primary emissions in urban area, black carbon (BC) is primarily from incomplete fossil fuel combustion. Light absorption of $\mathrm{BC}$ aerosols is increased after atmospheric aging by coating with secondary materials and restructuring (Khalizov et al., 2009). Due to cooling effects at the surface and warming effects aloft, the enhanced light absorption and scattering by aged $\mathrm{BC}$ particles stabilize the atmosphere, hindering vertical transport of gaseous and particulate pollutants (Wang et al., 2013). BC aging occurs much more efficiently in the presence of highly elevated gaseous aerosol precursors so that light absorption increases by a factor of 2.4 within $4.6 \mathrm{~h}$ under highly polluted conditions in Beijing, significantly exacerbating pollution accumulation and strongly contributing to severe haze formation (Peng et al., 2016).

Due to the implementation of several effective regulatory policies, the increasing trend of primary emissions has been under control since the 11th 5-year period. A growing number of studies have suggested that secondary production was the major contributor to the haze events in recent years (Shi et al., 2014; Zhao et al., 2013; Zhang et al., 2015; Huang et al., 2014), in contrast to the fact that primary emissions were of great importance in some haze events (Niu et al., 2016). Guo et al. (2014) reported that the development of PM episodes in Beijing was characterized by efficient nucleation and continuous particle growth over an extend period dominated by local secondary formation. They attributed the continuous growth of particle size and constant accumulation of particle mass concentration to the highly elevated concentrations of gaseous precursors such as $\mathrm{NO}_{x}, \mathrm{SO}_{2}$, and volatile organic compounds (VOCs), while the contribution from primary emissions and regional transport was negligible. However, the role of regional transport of $\mathrm{PM}_{2.5}$ in haze formation remains controversial (Li et al., 2015; Zhang et al., 2015a).

The most important advances in the understanding of urban PM formation were reviewed by Zhang et al. (2015b). The concentrations of $\mathrm{SO}_{2}, \mathrm{NO}_{x}$, and anthropogenic source VOCs in Beijing and other cities in the developing world are significantly higher than those in the urban areas of developed countries, resulting in large secondary production of sulfate, nitrate, and secondary organic aerosol. Synergetic effects among various organic and inorganic compounds may exist under highly polluted conditions, indicating different PM formation rates between developing and developed urban regions. Indeed, a large enhancement of particulate sulfate was typically observed during regional haze events in China (Chen et al., 2016; Wang et al., 2015; Fu et al., 2008; Xie et al., 2015). Currently, the highly elevated sulfate concentration during haze events cannot be fully explained by model simulations (Wang et al., 2014a; Chen et al., 2016). Recently, a significant breakthrough made by Wang et al. (2016) has provided a reasonable explanation about the high level of sulfate during haze events. It was revealed by their laboratory experiments that the aqueous oxidation of $\mathrm{SO}_{2}$ by $\mathrm{NO}_{2}$ proceeds more efficiently with the increase of $\mathrm{NO}_{2}$ concentration, whereas the reaction is suppressed in acid conditions because acid effect reduces the solubility of $\mathrm{SO}_{2}$ and reaction rate. The enhanced sulfate formation during severe haze periods in Beijing was attributable to aqueous oxidation of $\mathrm{SO}_{2}$ by $\mathrm{NO}_{2}$ on hygroscopic fine particles under conditions of elevated $\mathrm{RH}$ and the concentrations of $\mathrm{NH}_{3}$ and $\mathrm{NO}_{2}$, as confirmed by the comparable $\mathrm{SO}_{2}$ uptake coefficients for sulfate formation from field and laboratory results.

The hygroscopic properties of ambient particles vary significantly depending on the origin of the air masses and the atmospheric aging process. In urban air, the population of near-hydrophobic particles can be assumed to consist largely of freshly emitted combustion particles containing high mass fractions of soot and water-insoluble organic compounds (Swietlicki et al., 2008; Massling et al., 2009). In contrast, secondary sulfate or nitrate aged particles are more hygroscopic, and their relative abundance is primarily responsible for the hygroscopic growth of ambient particles at elevated RH (Topping et al., 2005; Aggarwal et al., 2007; Gysel et al., 2007). Thus, hygroscopicity can serve as a tracer of source origins, mixing state, and aging mechanisms of ambient particles. For example, the temporal variation of aerosol hygroscopicity has thrown new light on haze formation mechanisms in Beijing and Shanghai (Ye et al., 2011; Guo et al., 2014).

Density is one of the most important physicochemical properties for atmospheric aerosols. Effective density has served as a tracer for new particle formation (NPF) and for the aging process in previous studies (Yin et al., 2015; Guo et al., 2014). The ambient particles in urban areas are mostly complex mixtures of elemental carbon (EC), organics (OC), and secondary inorganic aerosols (SIA) (Hu et al., 2012). The effective density of nascent traffic particles varies from approximately $0.9 \mathrm{~g} \mathrm{~cm}^{-3}$ to below $0.4 \mathrm{~g} \mathrm{~cm}^{-3}$, decreasing with the increase of particle size, because there are more voids between primary particles in relatively larger aggregates (Momenimovahed and Olfert, 2015). The effective density of OC is in between that of EC and SIA and varies with source. The effective density of combustion particles increases by filling the voids in the agglomerate particles with condensed semivolatile materials or by restructuring agglomerates with hygroscopic SIA (Momenimovahed and Olfert, 2015; Zhang et al., 2008).

In this study, a combined HTDMA-APM (hygroscopic tandem differential mobility analyzer and aerosol particle 
mass analyzer) system was used to investigate the variations of hygroscopicity and effective density of submicrometer aerosols during winter 2014 in urban Shanghai. In addition, cascade impactor samples were collected and temporal variations of particle composition were determined by a single particle mass spectrometry, which provided further insight into the hygroscopicity and density variations. The primary objectives of this study were to investigate the particle growth mechanisms and to identify the contribution of local emissions during the winter haze events.

\section{Experimental}

\subsection{Sampling site}

The measurements of particle hygroscopicity and effective density were conducted from 21 December 2014 to 13 January 2015 at the Department of Environmental Science and Engineering on the main campus of Fudan University $\left(31.30^{\circ} \mathrm{N}, 121.5^{\circ} \mathrm{E}\right)$. It can be considered as a representative urban site for Shanghai. There are many dwelling quarters and commercial blocks in surrounding area. About $400 \mathrm{~m}$ away from the measurement site, there is the Middle Ring Line, one of the busiest elevated roads in the city.

\subsection{Measurements of air quality index and ground meteorological parameters}

At a supersite about $100 \mathrm{~m}$ away from the Environmental Building, $\mathrm{PM}_{1.0}$ was monitored using a Thermo Scientific ${ }^{\mathrm{TM}}$ 5030 SHARP monitor. Trace gas pollutants were monitored using Thermo Scientific ${ }^{\mathrm{TM}} \mathrm{i}$-series gas analyzers (43i for $\mathrm{SO}_{2}$, $49 \mathrm{i}$ for $\mathrm{O}_{3}, 42 \mathrm{i}$ for $\mathrm{NO} / \mathrm{NO}_{2} / \mathrm{NO}_{x}$ ), and meteorological data were monitored using an automatic meteorological station (model CAWS600, Huayun Inc., China) (Yin et al., 2015). The data of $\mathrm{PM}_{2.5}, \mathrm{PM}_{10}$, and $\mathrm{CO}$ were released by the Shanghai Environmental Monitoring Center. The height of the planetary boundary layer (PBL) was computed online using the NCEP Global Data Assimilation System (GDAS) model (http://ready.arl.noaa.gov/READYamet.php).

\subsection{HTDMA-APM system}

Particle size distribution, hygroscopic growth factor (GF), and effective density were measured using a custom-built HTDMA-APM system (Fig. 1). The custom-built HTDMAs mainly consist of two long DMAs (3081L, TSI Inc.), a humidifier (PD-50T-12MSS, Perma Pure Inc.), and a condensation particle counter (CPC, model 3771, TSI Inc.). A detailed description of the HTDMA is available in Ye et al. (2009). In this observation, particle number size distribution in the range of 14-600 nm and hygroscopic growth at $83 \% \mathrm{RH}$ for particles with dry diameters of 40,100, 220, 300,350, and $400 \mathrm{~nm}$ were determined by HTDMA in turn. The determination of effective density by DMA-APM was described pre-

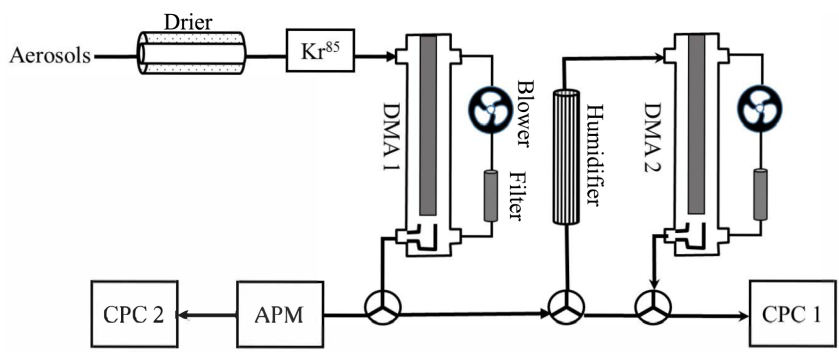

Figure 1. Schematic diagram of HTDMA-APM system.

viously (Yin et al., 2015; Pagels et al., 2009). Briefly, a combined system consisting of a compact APM (model 3601, Kanomax Inc.) and a CPC (model 3775, TSI Inc.) was connected to the sample tubing through a three-way electrical switch behind the upstream DMA (DMA1). The APM comprises two coaxial cylindrical electrodes rotating at the same angular velocity. Charged aerosol particles of a certain diameter sized by DMA1 are axially fed into the annular gap between the electrodes and experienced an outward centrifugal force from the particle rotating and an inward electrostatic force from the high-voltage field between the electrodes. Particles pass through the APM and are sent to the CPC when the two forces are balanced. The mass of particles that pass through the APM is determined by the rotation rate and the applied voltage. Effective densities for dry diameters of 40 , 100,220 , and $300 \mathrm{~nm}$ were determined by the method of DMA-APM in this study. The HTDMA-APM was operated alternatively in HTDMA mode and then DMA-APM mode, for every $40 \mathrm{~min}$.

Before the field observation, the HTDMA-APM was calibrated using $40-450 \mathrm{~nm}$ NIST-traceable polystyrene latex sphere particles and ammonium sulfate. The measured HTDMA data were inversed with the TDMA ${ }_{\text {inv }}$ algorithm to obtain the actual GF distribution. This is because the raw data are only a skewed and smoothed integral transform of the actual GF probability density function (GF-PDF) (Gysel et al., 2009). The hygroscopicity parameter $\kappa$ was derived from the GF data after inversion with the TDMA $\mathrm{inv}_{\text {inv }}$ algorithm according to the $\kappa$-Köhler theory (Petters and Kreidenweis, 2007).

\subsection{Single particle aerosol mass spectrometry (SPAMS)}

A SPAMS (Hexin Analytical Instrument Co., Ltd., China) installed in the same room with the HTDMA-APM system was used to obtain the chemical and size information of individual particles in the range of $0.2-2 \mu \mathrm{m}$. Detailed information on SPAMS is available in Li et al. (2011). Briefly, ambient particles are drawn into a vacuum chamber through an aerodynamic focusing lens and accelerated to a size-dependent terminal velocity. Sized particles are desorbed and ionized by the pulsed desorption/ionization laser (Q-switched $\mathrm{Nd}$ : YAG, $\lambda=266 \mathrm{~nm}$ ) at the ion source region. Both positive and negative mass spectra for a single particle are recorded 


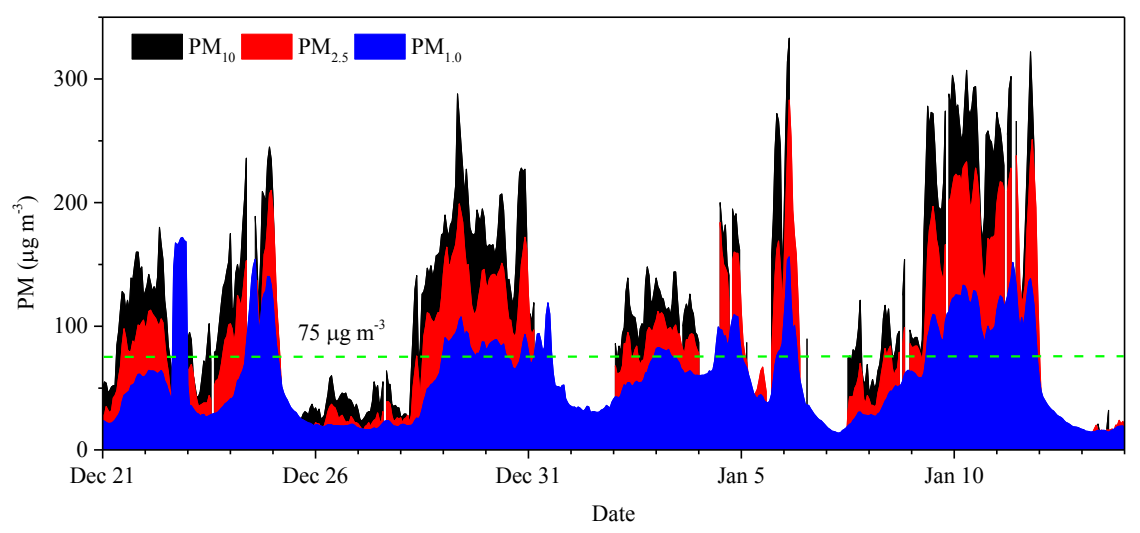

Figure 2. Temporal evolutions of $\mathrm{PM}_{1.0}, \mathrm{PM}_{2.5}$, and $\mathrm{PM}_{10}$ concentrations during the winter observation.

by a bipolar time-of-flight spectrometer. The single particle information was imported into YAADA (version 2.11, www.yaada.org). Based on the similarities of the mass-tocharge ratio and peak intensity, particles were classified using the ART-2a method.

\subsection{Ion chromatography}

Cascade impactor aerosol samples for offline analysis were collected at the roof platform of the Environmental Building using a 10-stage MOUDI sampler (micro-orifice uniform deposit impactor, model 110-NR, MSP Corp., USA). A detailed description of the sampling, pretreatment, chemical analysis, and quality control of this system is available in Tao et al. (2016). Briefly, cascade impactor samples were collected every $24 \mathrm{~h}$ using the PALL7204 quartz filter as the collection substrate. Each filter was weighted with a BP211D electronic balance at $25 \pm 1{ }^{\circ} \mathrm{C}$ and $40 \pm 2 \% \mathrm{RH}$. The water extract of each sample was analyzed using an ion chromatograph (Metrohm 883 basic IC plus, Switzerland) equipped with a third-party column heater (CT-100, Agela Corp., China). Seven anions $\left(\mathrm{F}^{-}, \mathrm{Cl}^{-}, \mathrm{NO}_{2}^{-}, \mathrm{Br}^{-}, \mathrm{NO}_{3}^{-}\right.$, $\mathrm{SO}_{4}^{2-}$, and $\mathrm{PO}_{4}^{3-}$ ) were resolved using a Metrosep A Supp $5-250 / 4.0$ column at $35^{\circ} \mathrm{C}$ with an eluent of $3.2 \mathrm{mmol} \mathrm{L}^{-1}$ $\mathrm{Na}_{2} \mathrm{CO}_{3}+1.0 \mathrm{mmol} \mathrm{L}^{-1} \mathrm{NaHCO}_{3}$. Six cations $\left(\mathrm{Li}^{+}, \mathrm{Na}^{+}\right.$, $\mathrm{NH}_{4}^{+}, \mathrm{K}^{+}, \mathrm{Ca}^{2+}$, and $\mathrm{Mg}^{2+}$ ) were separated by a Metrosep $\mathrm{C} 4-250 / 4.0$ column at $30^{\circ} \mathrm{C}$ with an eluent of $1.7 \mathrm{mmol} \mathrm{L}^{-1}$

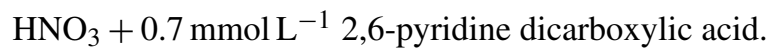

\section{Results and discussion}

\subsection{Periodic cycle of PM episodes during the observation period}

Figure 2 shows the temporal variations of PM mass loading during the winter observation (21 December 2014 to 13 January 2015). The official data of $\mathrm{PM}_{2.5}$ and $\mathrm{PM}_{10}$ were blank on some clean days. Meteorologically, our measurement was deployed in a typical winter period. The average concentrations of $\mathrm{PM}_{1.0}, \mathrm{PM}_{2.5}$, and $\mathrm{PM}_{10}$ were $57 \pm 37,87 \pm 67$, and

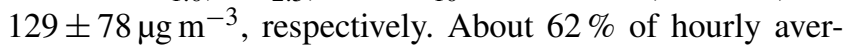
aged $\mathrm{PM}_{2.5}$ concentrations exceeded $75 \mu \mathrm{g} \mathrm{m}^{-3}$ of the Chinese Grade II guideline (GB 3095-2012), indicating heavy particle pollution in Shanghai during wintertime. The PM episodes exhibited a clear periodic cycle of $\sim 5$ days. A similar feature was previously observed in Beijing (Guo et al., 2014). At the beginning of each cycle, the $\mathrm{PM}_{1.0}$ level was below $35 \mathrm{\mu g} \mathrm{m}^{-3}$. Generally, the difference between the concentrations of $\mathrm{PM}_{1.0}$ and $\mathrm{PM}_{2.5}$ during clean days was less significant than that in haze periods. Occasionally the measured $\mathrm{PM}_{2.5}$ concentrations were larger than those of $\mathrm{PM}_{10}$, possibly due to system error. However, the particle mass concentration began to increase in the next few days, with $\mathrm{PM}_{1.0}$ and $\mathrm{PM}_{2.5}$ peaking at over 100 and $200 \mu \mathrm{g} \mathrm{m}^{-3}$, respectively. During the end of each PM episode, the change in weather conditions played a key role in the decrease of particle concentration. As shown in Fig. S1 in the Supplement, the prevailing winds on haze days were from the northwest. The prevailing winds during two clean periods (25-27 December and 12-14 January) were northeasterly, bringing clean air mass from the East China Sea. Two cold fronts from the north swept Shanghai on 31 December and 6 January, bringing gale and lower temperatures which favored the dispersion of atmospheric pollutants.

\subsection{Contributions of SIA to $\mathbf{P M}_{1.0}$ mass loading}

Figure 3 illustrates the daily concentrations of sulfate, nitrate, and ammonium (SNA) as a function of $\mathrm{PM}_{1.0}$ mass loading. In general, the sum of concentrations of SNA increased linearly as the $\mathrm{PM}_{1.0}$ mass loading increased. It is noticeable that the SNA $/ \mathrm{PM}_{1.0}$ ratio slightly fluctuated around 0.28 , regardless of the pollution level. Because soil dust and sea salt made a negligible contribution to the fine particle mass concentration in this study, the almost constant ratio of SNA / $\mathrm{PM}_{1.0}$ indicates that SNA and carbonaceous aerosols (including soot and organic matter) synchronously 


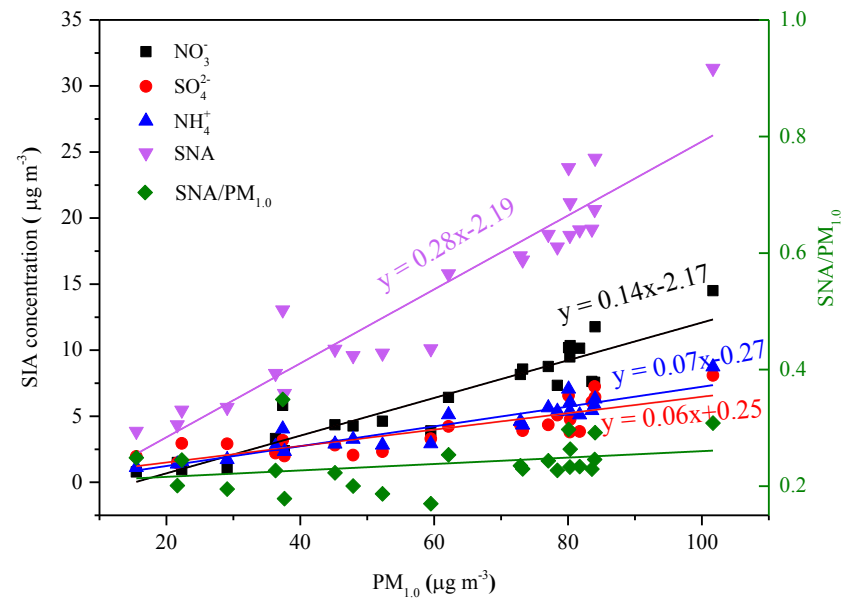

Figure 3. Variations of sulfate, nitrate, and ammonium concentrations as a function of $\mathrm{PM}_{1.0}$ mass loading.

increased during the haze events. As the $\mathrm{PM}_{1.0}$ concentration increased, the concentration of nitrate increased more rapidly than sulfate so that it became the most abundant ionic species at $\mathrm{PM}_{1.0}>40 \mu \mathrm{g} \mathrm{m}^{-3}$. This finding indicates that $\mathrm{NO}_{x}$ contributed more to haze formation in Shanghai compared to $\mathrm{SO}_{2}$. Generally, the visibility decreased with the increase in PM concentration, indicating photochemical activity began to weaken as the development of haze events. The large increase in nitrate concentration may be attributable to heterogeneous reaction on the preexisting particles. Nitrate formation is highly dependent on the surface area of preexisting particles and is favored under $\mathrm{NH}_{3}$-rich conditions (Chu et al., 2016). In contrast, Han et al. (2016) reported that the mass ratio of nitrate to sulfate decreased with the increase of $\mathrm{PM}_{2.5}$ level and that the sources of sulfate contributed more to the haze formation in Beijing than mobile sources. This finding suggests that the haze formation mechanism in Shanghai is likely different from that in Beijing. VOCs and $\mathrm{NO}_{x}$ are exclusively from local emissions whereas regional transport is a big source of $\mathrm{SO}_{2}$ under stagnant atmosphere due to different atmospheric lifetimes among $\mathrm{SO}_{2}, \mathrm{NO}_{x}$, and VOCs (Guo et al., 2014). Considering the relatively smaller contribution of sulfate, our results reveal that the accumulation and secondary transformation of local emissions likely played a dominant role in this haze formation.

\subsection{Aerosol hygroscopicity and effective density during the observation period}

Figure $4 \mathrm{a}$ displays a box chart of the mean hygroscopicity of each hygroscopic GF distribution for different sizes. Considering all of the GF distributions collectively, the hygroscopicity parameter $\kappa$ increased with an increase of the dry diameter, with a mean $\kappa$ of 0.161 at $40 \mathrm{~nm}$ and 0.338 at $300 \mathrm{~nm}$. Assuming a two-component system of a model salt (ammonium sulfate, $\kappa_{m}=0.53$ ) and an insoluble species
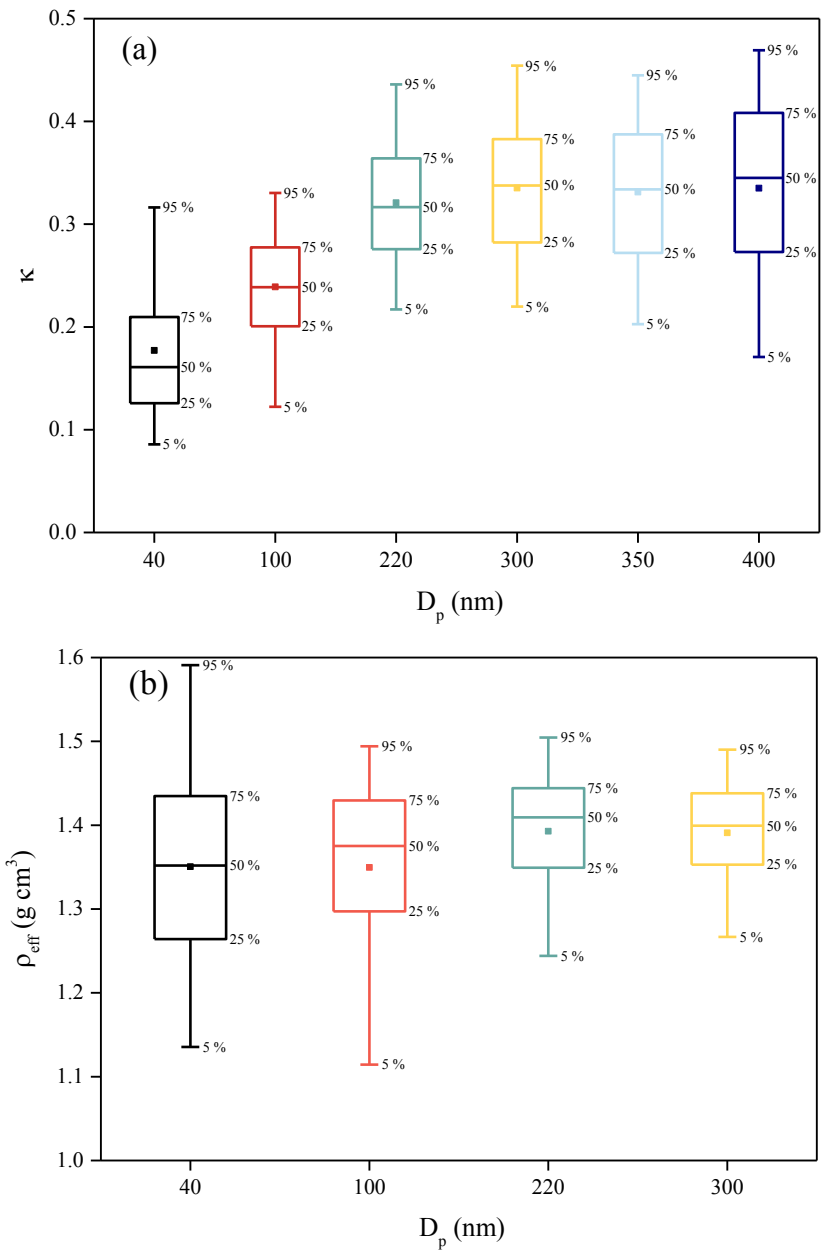

Figure 4. Box plots showing hygroscopicity parameter and effective density at each dry diameter over the whole observation. The whiskers represent the 5th and 95th percentile, the two borders of box display the 25 th and 75 th percentile, and the band in each box denotes the median.

$(\kappa=0)$, the volume fraction of hygroscopic species $(\varepsilon)$ can be obtained based on the Zdanovskii-Stokes-Robinson mixing rule. The average $\varepsilon$ was 0.3 for $40 \mathrm{~nm}$ particles, suggesting that the primary particles or initial growth of freshly generated particles were dominated by non-hygroscopic species. In contrast, the $300 \mathrm{~nm}$ particles were extremely aged, with more-hygroscopic species.

Generally, HTDMAs measure dry particles smaller than $300 \mathrm{~nm}$ due to technical limitations, and it is common that particle hygroscopicity increases with the increase of particle size (Liu et al., 2014; Swietlicki et al., 2008). The increase of particle hygroscopicity with particle size was attributed to the addition of more-hygroscopic SNA (Swietlicki et al., 2008; Ye et al., 2010). The very few measurements for dry particles larger than $300 \mathrm{~nm}$ showed different size dependencies. Gasparini et al. (2006) reported that particle hygroscopicity first increased and then decreased with the increase of 


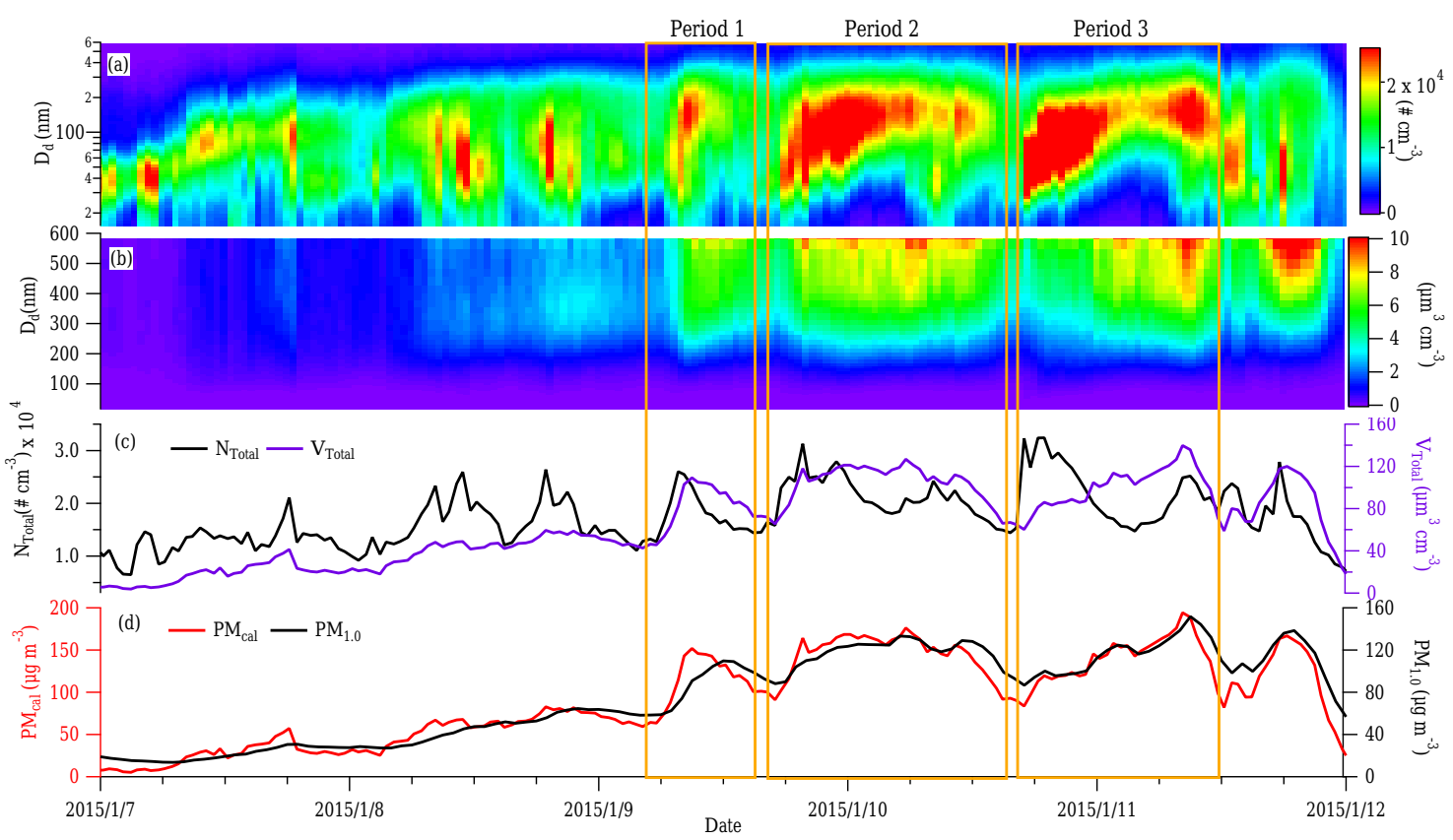

Figure 5. Temporal evolutions of particle number size distribution (a), volume size distribution (b), total number concentration and total volume concentration (c), and $\mathrm{PM}_{1.0}$ concentration and calculated PM (less than $600 \mathrm{~nm}$ in mobility diameter) concentration during the representative PM episode from 7 to 12 January.

particle size, peaking at the diameter of $300 \mathrm{~nm}$. In contrast, Z. J. Wu et al. (2016) reported that particle hygroscopicity increased with particle diameter in the range of $35-350 \mathrm{~nm}$. In this study, the determination size range was extended to $400 \mathrm{~nm}$ and the mean $\kappa \mathrm{s}$ of 300,350 , and $400 \mathrm{~nm}$ particles were nearly equal. We attribute the different size dependencies of hygroscopicity among various measurement sites to the total emissions of $\mathrm{SO}_{2}$ and $\mathrm{NO}_{x}$, gas precursors of hygroscopic sulfate and nitrate. It is noticeable that the 5th percentile hygroscopicity decreased for dry diameter larger than $300 \mathrm{~nm}$, likely due to the presence of the smallest dust particles (Gasparini et al., 2006). The variability of hygroscopicity parameter $\kappa$ was much greater for $40 \mathrm{~nm}$ particles. The particle population with $\kappa<0.1$ was attributed to fresh traffic particles (Ye et al., 2013). The considerable percentile of $\kappa<0.1$ indicates that the $40 \mathrm{~nm}$ particle population was sometimes dominated by near-hydrophobic particles.

Figure $4 \mathrm{~b}$ displays a box chart of median effective density for different particle sizes. The median effective density varied in the narrow range of $\rho_{\text {eff }}=1.35-1.41 \mathrm{~g} \mathrm{~cm}^{-3}$ for $40-300 \mathrm{~nm}$ particle population. The size dependency of particle effective density varied in the literature. $\mathrm{Hu}$ et al. (2012) and Yin et al. (2015) reported that effective density of the particles increased as particle size increased while a opposite trend was observed by Geller et al. (2006) and Spencer et al. (2007). The different trends were attributable to the variable fraction of lower-density mode particles $\left(\rho_{\text {eff }}<1.0 \mathrm{~g} \mathrm{~cm}^{-3}\right)$. The densities of the secondarily produced $\left(\mathrm{NH}_{4}\right)_{2} \mathrm{SO}_{4}, \mathrm{NH}_{4} \mathrm{HSO}_{4}$, and $\mathrm{NH}_{4} \mathrm{NO}_{3}$ are $\sim 1.75 \mathrm{~g} \mathrm{~cm}^{-3}$. The effective density of organic aerosols varies mostly in the range of $1.2-1.6 \mathrm{~g} \mathrm{~cm}^{-3}$, depending on their source origins (Malloy et al., 2009; Turpin and Lim, 2001; Dinar et al., 2006). The lower-density particles with $\rho_{\text {eff }}<1.0 \mathrm{~g} \mathrm{~cm}^{-3}$ were attributable to fresh or partially aged traffic-related particles because the number fraction of the lower-density group in urban area was found to be consistent with the concentration of NO (indicator of traffic) (Levy et al., 2013; Rissler et al., 2014). Although the dominant accumulation-mode particles have an effective density greater than Aitken-mode ones, the presence of a lower effective density group associated with traffic emissions might decrease the mean effective density to a value lower than that of Aitken-mode particles (Levy et al., 2014). Yin et al. (2015) reported that effective density distributions were dominated by a single peak in the previous observation. In contrast, a lower-density peak below $1.0 \mathrm{~g} \mathrm{~cm}^{-3}$ was often present in this observation, decreasing the mean effective density of externally mixed aerosols.

\subsection{Characteristics of a representative PM episode}

As shown in Fig. 2, the PM episode from 7 to 12 January was a representative case of severe haze formation and elimination processes. It can be divided into clean (7 January), transition (8 January), haze (9-11 January), and posthaze (12 January) periods. During the transition from the clean period to haze period (7 to 8 January), both $\mathrm{PM}_{1.0}$ and $\mathrm{PM}_{2.5}$ concentrations increased slightly, with an aver- 

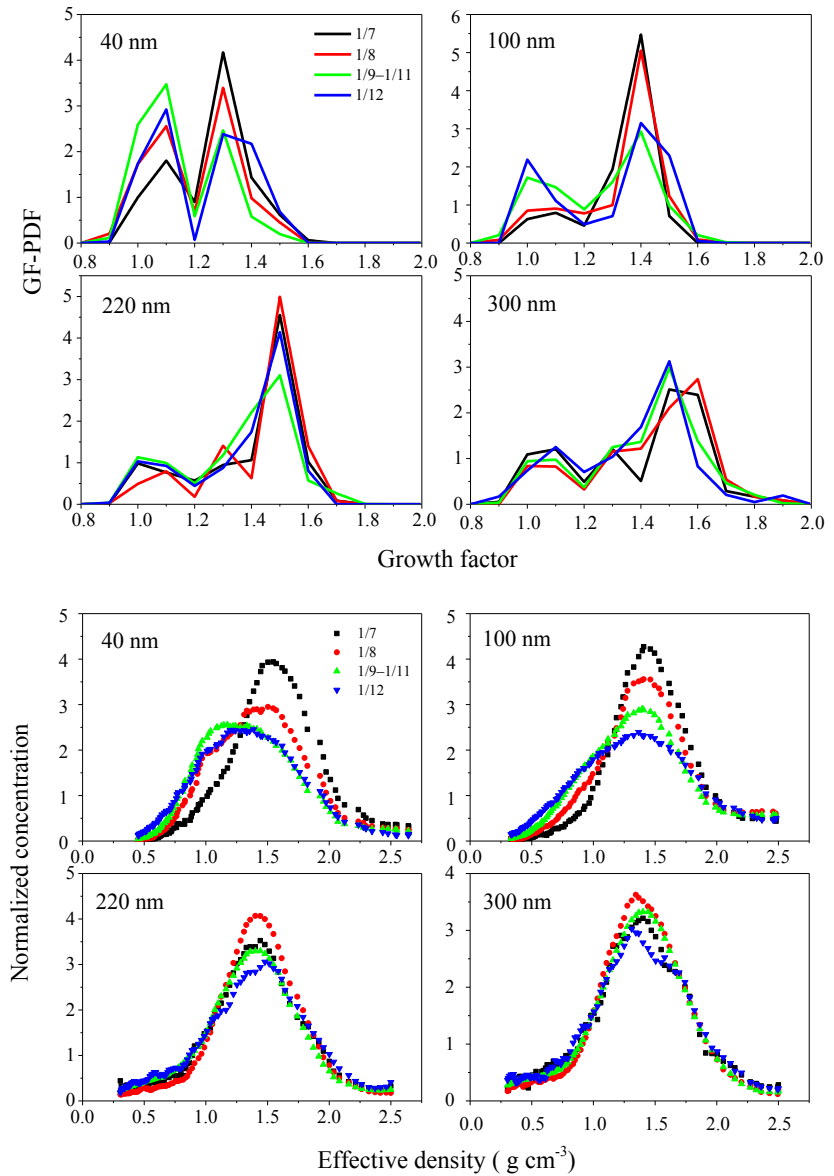

Figure 6. Evolutions of particle hygroscopic growth factor and effective density for different sizes during the representative PM episode.

age $\mathrm{PM}_{1.0} / \mathrm{PM}_{2.5}$ ratio of 0.65 . A sharp increase in $\mathrm{PM}_{2.5}$ (of $125 \mu \mathrm{g} \mathrm{m}^{-3}$ ) was observed from 06:00 to 12:00 LT on the morning of 9 January. During the haze period, the concentration of $\mathrm{PM}_{2.5}$ exceeded $115 \mu \mathrm{g} \mathrm{m}^{-3}$ (medially polluted level, HJ633-2012) for $63 \mathrm{~h}$. On 11 January, the hourly $\mathrm{PM}_{2.5}$ concentration exceeded $250 \mu \mathrm{g} \mathrm{m}^{-3}$, corresponding to the severely polluted level.

Figure 5 displays the temporal profile of particle size distribution, along with the measured $\mathrm{PM}_{1.0}$ concentration during the representative PM episode. The calculated PM concentrations $\left(\mathrm{PM}_{\mathrm{cal}}\right)$ were obtained based on the particle size distribution and average effective density of $1.39 \mathrm{~g} \mathrm{~m}^{-3}$ in the range of $14-600 \mathrm{~nm}$ measured in this study. It is noticeable that the temporal trends in mass concentrations of $\mathrm{PM}_{\mathrm{cal}}$ and $\mathrm{PM}_{1.0}$ are highly consistent. In contrast to the fact that particle size distribution was dominated by nanoparticles during the clean period, the burst of Aitken-mode particles and subsequent continuous growth to approximately $200 \mathrm{~nm}$ in diameter was observed three times during the haze period, indicating that the presence of numerous larger particles is likely responsible for the severe particle pollution (Guo et al., 2014). The importance of larger particles in haze formation is also illustrated by the contour plot of the particle volume size distribution. The difference of particle number concentration between transition and haze periods was less significant, whereas the volume concentration increased considerably during the haze period. This feature clearly demonstrates that the haze formation was closely correlated with particle growth and elevated number of larger particles.

Interestingly, the particle mass concentration was sensitive to variations of wind speed and PBL. During the transition and haze periods, the wind speed decreased considerably with insignificant change in prevailing wind (Fig. S1). This finding indicates that outside transportation became less and less significant. It is noteworthy that the temporal evolution of the particle mass concentration was inversely correlated with the PBL height. The decreasing PBL provided a stagnant atmosphere that favored the accumulation of local emissions. This finding reveals that the severe haze pollution was likely triggered by the adverse meteorological conditions. The impact of decreasing PBL height on haze formation can also be evidenced by the variations of trace gaseous species (Fig. S2). During the PM episode, the concentrations of $\mathrm{NO}_{2}, \mathrm{SO}_{2}$, and $\mathrm{CO}$ displayed variation trends similar to that of the particle concentration. The fluctuations of trace gas concentrations were caused by primary emission and secondary processes. Noticeably, the concentration of NO increased dramatically in rush hours during the haze period whereas it fluctuated slightly during the clean period, indicating that local emissions were easily accumulated under stagnant atmosphere. In addition, the maximum concentration of $\mathrm{O}_{3}$ remained considerably higher during daytime, whereas it decreased significantly at night. The most plausible explanation is that $\mathrm{O}_{3}$ was consumed rapidly by the accumulated trace gases, such as $\mathrm{NO}_{x}$, and VOCs.

\subsection{Variations of hygroscopicity and effective density during the PM episode}

Figure 6 shows the averaged hygroscopicity and effective density for different pollution periods of the PM episode. Regardless of the pollution period, the nearly hydrophobic particles were externally mixed with some hygroscopic particles. During the clean period, the more-hygroscopic particles dominated the $40 \mathrm{~nm}$ particle population, indicating that the near-hydrophobic primary particles were rapidly dispersed due to atmospheric dilution. The number fraction of the nearhydrophobic group for different sizes increased as the PM episode developed, indicative of the increasing accumulation of local emissions. Notably, the increase of the nearhydrophobic particles with the evolution of the PM episode become less significant as particle size increased, indicating that primary emission exerted a more significant impact on smaller particles than on larger ones. The median diameter of nascent traffic particles from various gasoline sources ranged 


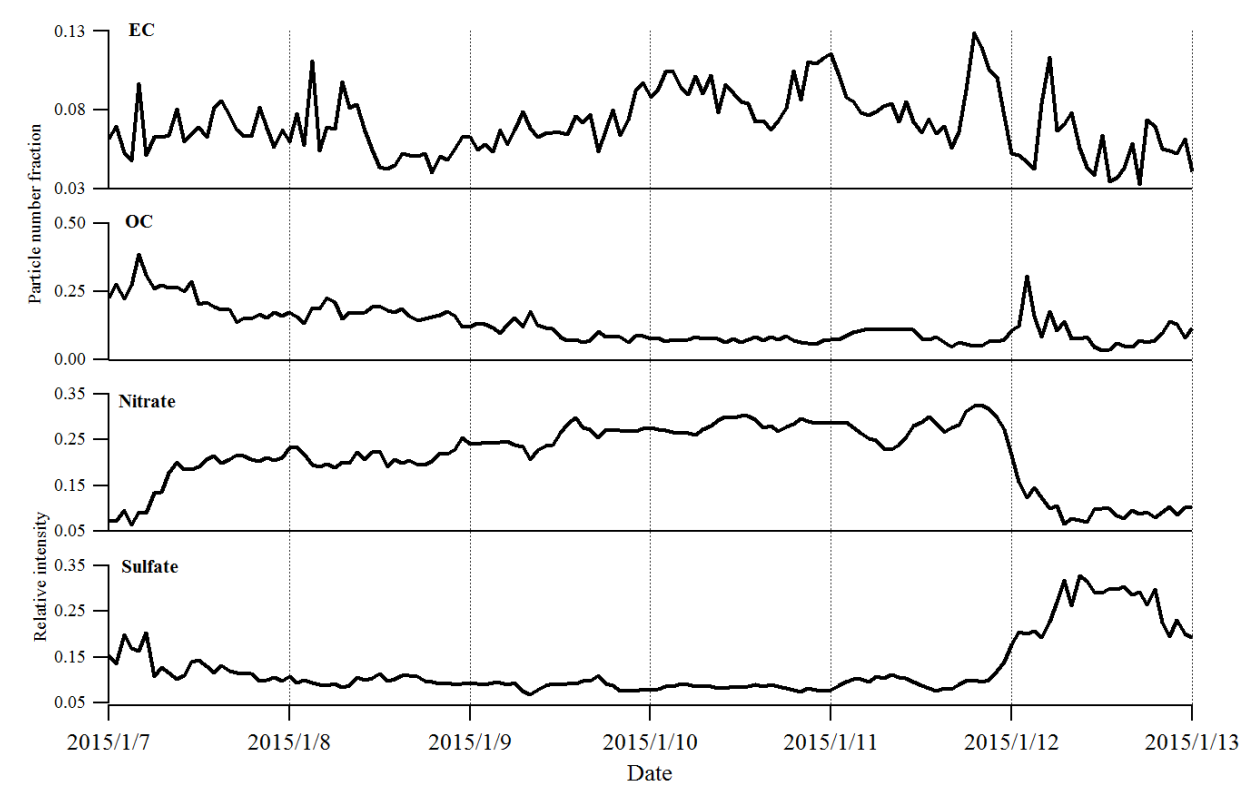

Figure 7. Temporal evolutions of chemical compositions determined by SPAMS during the representative PM episode.

between 55 and $73 \mathrm{~nm}$ with an average of $65 \mathrm{~nm}$ (Momenimovahed and Olfert, 2015). Therefore, the number fraction of the near-hydrophobic particles larger than $200 \mathrm{~nm}$ is not sensitive to the accumulation of traffic emissions.

Interestingly, the variations of particle effective density for different sizes are in good agreement with the hygroscopicity. The dominant peak of effective density distribution appeared at $\rho_{\text {eff }}=\sim 1.5 \mathrm{~g} \mathrm{~cm}^{-3}$ for $40 \mathrm{~nm}$ particles in the clean period, indicating that they are highly aged with hygroscopic inorganic salts (Yin et al., 2015). As the episode developed, the mean density shifted to lower values, indicating the increasing contribution of lower-density carbonaceous materials. The averaged density distribution was broadened as the episode developed, suggesting that it could be deconvolved into two groups and that the number fraction of the lowdensity group increased. This finding revealed that the lowerdensity particles are less hygroscopic whereas the largerdensity group corresponds to the more-hygroscopic one. In addition, the variations of hygroscopicity and effective density coincided with the evolution of PBL height, indicating that the increasing accumulation of local emissions due to adverse atmospheric conditions is likely responsible for the enhancement of those near-hydrophobic and lower-density particles.

Figure 7 displays the temporal profiles for contributions of EC (including bare EC and OC-coated EC), OC, sulfate, and nitrate determined by SPAMS. Obviously, the relative contribution of nitrate increased as the episode developed. In contrast, the relative contribution of sulfate displayed an opposite trend. This feature is comparable with the aforementioned results of SNA, thus further highlighting the important role of nitrate in haze formation in Shanghai. The number fraction of EC particles generally increased during the haze period, peaking at midnight on 9 and 10 January. It should be pointed out that the measured number fraction possibly underestimated the contribution of EC particles because the dominant size range of fresh traffic particles is below the detection limit of SPAMS $(0.2-2.0 \mu \mathrm{m})$. This finding provides good support for the increase of near-hydrophobic and lowerdensity particles as the episode developed. Niu et al. (2016) reported that the number ratio of secondary particles to soot in haze samples was higher than that collected in the clean days in Beijing. Our finding is comparable to their results. In contrast, the number fraction of pure OC decreased during the pollution event. The possible explanation is that the condensation of organic matter was favored on the large amount of preexisting EC particles or that photo-oxidation of VOCs was minimized due to lower solar radiation.

\subsection{Evolutions of hygroscopicity and effective density with particle growth}

As shown in Fig. 5, three "banana-shaped" evolutions of the particle size distribution were identified in the representative PM episode. The banana-type contour plot of particle size distributions is a typical characteristics of NPF events and traditionally regarded as one of the most important criteria for identifying NPF (Xiao et al., 2015; Dal Maso et al., 2005; Levy et al., 2013; Zhang et al., 2012). Atmospheric NPF is often defined by the burst of nucleation-mode particles and subsequent growth of the nuclei to larger particles (Zhang et al., 2012; Kulmala et al., 2012). Gas-phase sulfuric acid produced via oxidation of $\mathrm{SO}_{2}$ by $\mathrm{OH}$ radical plays a dominant role in the NPF events. NPF is typically 

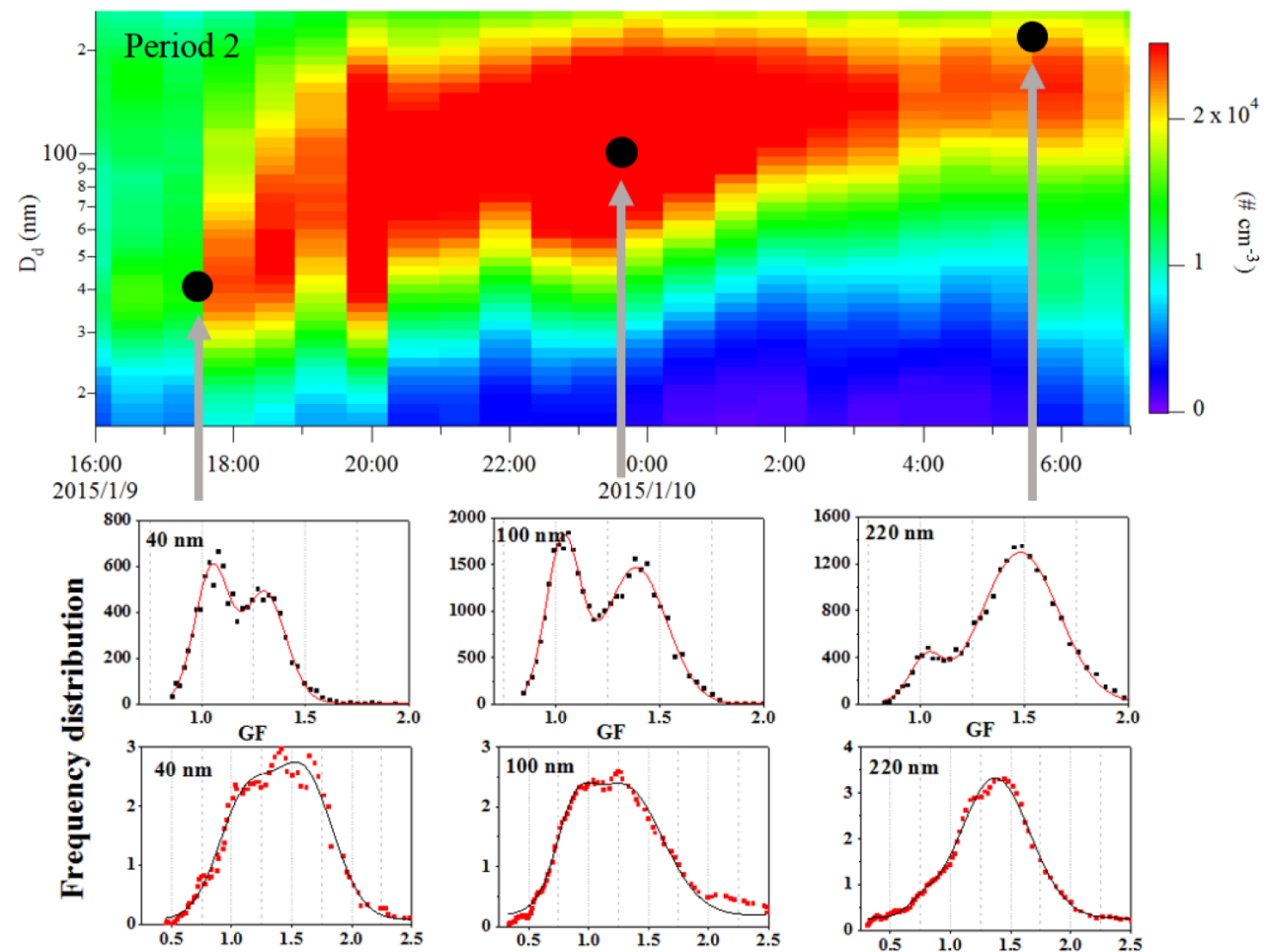

17:00 $\rho_{\text {efr }}\left(\mathrm{g} \mathrm{cm}^{-3}\right)$

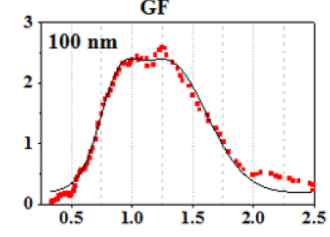

23:00 $\rho_{\text {eff }}\left(\mathrm{g} \mathrm{cm}^{-3}\right)$

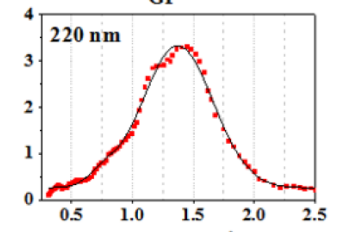

$5: 00 \quad \rho_{\text {efr }}\left(\mathrm{g} \mathrm{cm}^{-3}\right)$

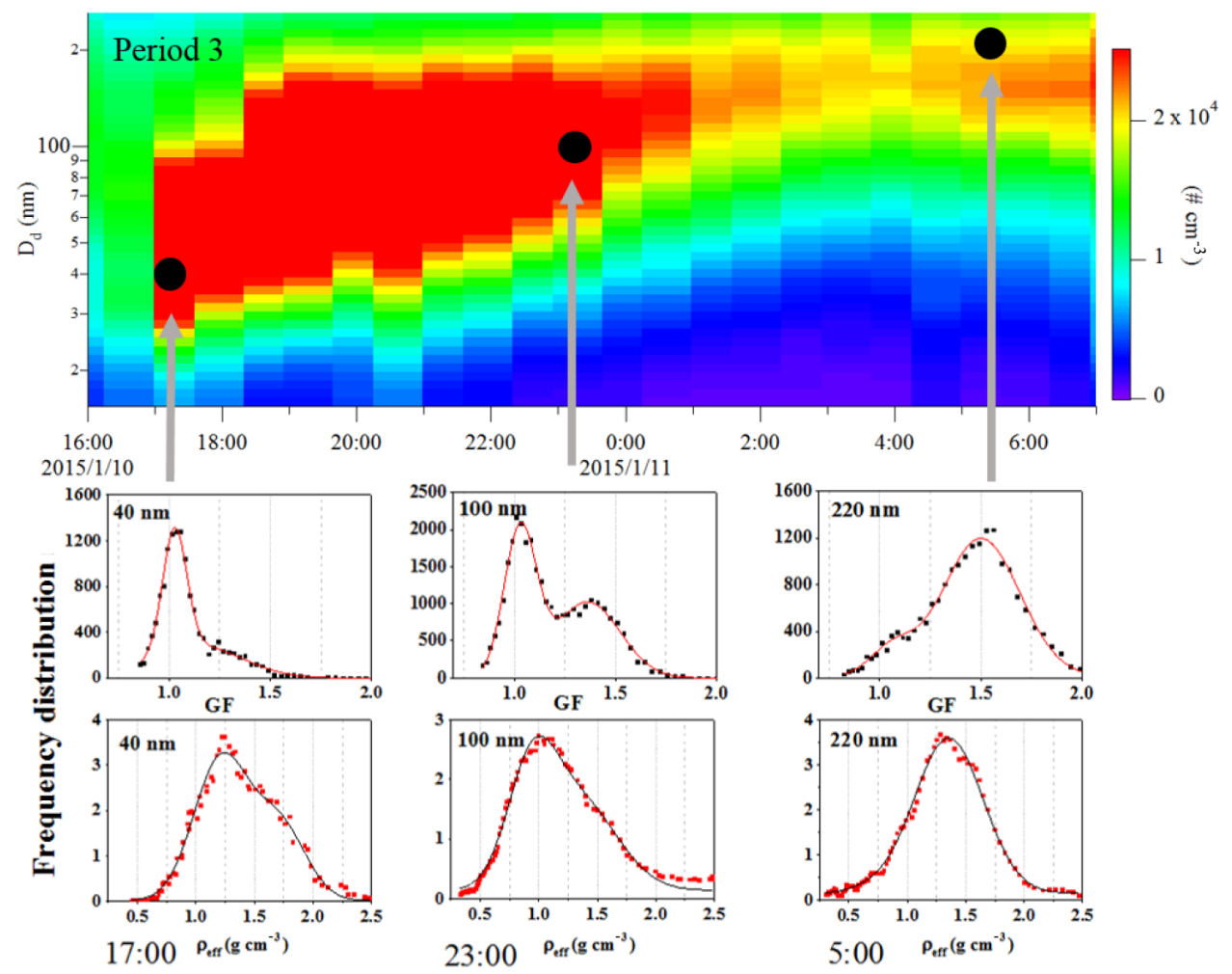

Figure 8. Particle hygroscopicity and density during the two particle growth processes. 
completely suppressed when preexisting particles is abundant, because gas-phase sulfuric acid is rapidly lost to the surfaces of preexisting aerosols (Zhang et al., 2012). In addition to sulfuric acid, low-volatility organic species and interaction between sulfate and organics are important for NPF (Zhang et al., 2004; Zhao et al., 2009). However, the possibility of NPF can be ignored in this study due to the absence of the burst of nucleation-mode particles and the high concentration of $\mathrm{PM}_{1.0}$. The burst of Aitken-mode particles in the current study may be attributable to rapid accumulation of traffic emissions during rush hours under stagnant atmospheric conditions. The banana-shaped particle growth in the time evolution of particle size distribution from the Aitkenmode size range to accumulation-mode size range was primarily due to coagulation and condensation processes. This feature provided an excellent opportunity to reveal the chemical mechanism of particle growth during the PM episode.

The first banana-shaped evolution of the particle size distribution occurred from approximately 05:00 to 15:00 LT on 9 January, with an increase of the particle number concentration $\left(N_{\text {total }}\right)$ from $1.7 \times 10^{4}$ to $3.4 \times 10^{4} \mathrm{~cm}^{-3}$ followed by a decrease until 17:00 LT (Period 1). The second bananashaped evolution occurred from approximately 18:00 LT on 9 January to approximately 12:00 LT on 10 January (Period 2). The $N_{\text {total }}$ increased from $2.1 \times 10^{4}$ to $4.2 \times 10^{4} \mathrm{~cm}^{-3}$ within $3 \mathrm{~h}$, followed by gradual decrease of $N_{\text {total }}$ in contrast to a continuous increase of the particle mass concentration. During the growth process, the mode diameter of the particle population increased from below $40 \mathrm{~nm}$ to approximately $200 \mathrm{~nm}$. The third banana-shaped evolution began in the evening rush hours on 10 January, with the continuous increase of PM mass concentration for $12 \mathrm{~h}$ (Period 3). The latter two banana-shaped evolutions lasted long enough to trace the changes in hygroscopicity and effective density due to particle growth.

Figure 8 illustrates the evolution of particle hygroscopicity and effective density during periods 2 and 3. During the initial stage, the measured GF and effective density distributions were both bimodal, with a dominant peak at $\mathrm{GF}=\sim 1.0$ and $\rho_{\text {eff }}=\sim 1.0 \mathrm{~g} \mathrm{~cm}^{-3}$, respectively. In a previous study, we found that the number fraction of near-hydrophobic particles varied with the traffic exhaust (Ye et al., 2013). Moreover, laboratory studies showed that the effective density of $50 \mathrm{~nm}$ vehicle particles was approximately $1.0 \mathrm{~g} \mathrm{~cm}^{-3}$ (Olfert et al., 2007; Park et al., 2003; Momenimovahed and Olfert, 2015). These findings indicate that the initial burst of Aitken-mode particles is attributable to the presence of enhanced trafficrelated emissions. In contrast, the number fraction and GF of the more-hygroscopic group increased with the growing particle size, indicating the addition of hygroscopic inorganic species. The variation of the effective density of the particles was similar to that of the hygroscopicity, indicating the increase of high-density materials. In general, inorganic sulfate and nitrate are more hygroscopic and denser than soot particles or organic aerosols (Yin et al., 2015). These find- ings suggest that secondary sulfate and nitrate increased with the growing particle size, indicating the importance of the conversion of $\mathrm{SO}_{2}$ and $\mathrm{NO}_{x}$ in particle growth. This conclusion is supported by the largest SNA concentration in $\mathrm{PM}_{1.0}$ during the $\mathrm{PM}$ episode $\left(31.3 \mu \mathrm{g} \mathrm{m}^{-3}\right.$ on 10 January and $23.8 \mu \mathrm{g} \mathrm{m}^{-3}$ on 11 January). Considering that the concentration of nitrate was much higher than that of sulfate during the haze event, the increase of hygroscopicity was dominated by the addition of nitrate.

\section{Conclusions}

Particle size distribution, size-resolved hygroscopic growth, and effective density of sub-micrometer aerosols were determined using a HTDMA-APM system, along with measurements of cascade impactor samples and single particle mass spectrometry in urban Shanghai during winter 2014.

The PM episode exhibited a periodic cycle of $\sim 5$ days. The average concentration of $\mathrm{PM}_{2.5}$ was $87 \pm 67 \mu \mathrm{g} \mathrm{m}^{-3}$, with approximately $62 \%$ of hourly $\mathrm{PM}_{2.5}$ concentrations exceeding the Chinese Grade II guideline. Both secondary inorganic salts and carbonaceous aerosols contributed substantially to haze formation because the mass ratio of SNA / $\mathrm{PM}_{1.0}$ fluctuated slightly around 0.28 during the observation period. Nitrate became the most abundant ionic species at $\mathrm{PM}_{1.0}>40 \mu \mathrm{g} \mathrm{m}^{-3}$, indicating that the sources of nitrate contributed more to haze formation in Shanghai than $\operatorname{did} \mathrm{SO}_{2}$.

The severe haze pollution was likely triggered by the adverse meteorological conditions, which favored the accumulation of local emissions and subsequent rapid growth to larger particles. As the PM episode developed, the number fraction of nearly hydrophobic particles of different size increased, consistent with decrease of the mean effective density. Both hygroscopicity and effective density of the particles were found to increase considerably with growing particle size, indicating that secondary aerosol formation was one of the most important contributors to particle growth. Our results suggest that the accumulation of local emissions under adverse meteorological conditions and subsequent rapid particle growth by secondary processes are primarily responsible for the haze pollution in Shanghai during wintertime.

Data availability. The data in the study are available from the authors upon request (yexingnan@fudan.edu.cn).

\section{The Supplement related to this article is available online at https://doi.org/10.5194/acp-17-7277-2017-supplement.}

Competing interests. The authors declare that they have no conflict of interest. 
Acknowledgements. This work was supported by the National Natural Science Foundation of China $(21477020,21527814$, and 91544224) and the National Science and Technology Support Program of China (2014BAC22B01).

Edited by: R. Zhang

Reviewed by: two anonymous referees

\section{References}

Aggarwal, S. G., Mochida, M., Kitamori, Y., and Kawamura, K.: Chemical closure study on hygroscopic properties of urban aerosol particles in Sapporo, Japan, Environ. Sci. Technol., 41, 6920-6925, https://doi.org/10.1021/es063092m, 2007.

Chen, D., Liu, Z., Fast, J., and Ban, J.: Simulations of sulfatenitrate-ammonium (SNA) aerosols during the extreme haze events over northern China in October 2014, Atmos. Chem. Phys., 16, 10707-10724, https://doi.org/10.5194/acp-16-107072016, 2016.

Chu, B., Zhang, X., Liu, Y., He, H., Sun, Y., Jiang, J., Li, J., and Hao, J.: Synergetic formation of secondary inorganic and organic aerosol: effect of $\mathrm{SO}_{2}$ and $\mathrm{NH}_{3}$ on particle formation and growth, Atmos. Chem. Phys., 16, 14219-14230, https://doi.org/10.5194/acp-16-14219-2016, 2016.

Dal Maso, M., Kulmala, M., Riipinen, I., Wagner, R., Hussein, T., Aalto, P. P., and Lehtinen, K. E. J.: Formation and growth of fresh atmospheric aerosols: eight years of aerosol size distribution data from SMEAR II, Hyytiala, Finland, Boreal Environ. Res., 10, 323-336, 2005.

Dinar, E., Mentel, T. F., and Rudich, Y.: The density of humic acids and humic like substances (HULIS) from fresh and aged wood burning and pollution aerosol particles, Atmos. Chem. Phys., 6, 5213-5224, https://doi.org/10.5194/acp-6-5213-2006, 2006.

Fu, Q. Y., Zhuang, G. S., Wang, J., Xu, C., Huang, K., Li, J., Hou, B., Lu, T., and Streets, D. G.: Mechanism of formation of the heaviest pollution episode ever recorded in the Yangtze River Delta, China, Atmos. Environ., 42, 2023-2036, 2008.

Gasparini, R., Li, R. J., Collins, D. R., Ferrare, R. A., and Brackett, V. G.: Application of aerosol hygroscopicity measured at the Atmospheric Radiation Measurement Program's Southern Great Plains site to examine composition and evolution, J. Geophys. Res.-Atmos., 111, D05S12, https://doi.org/10.1029/2004JD005448, 2006.

Geller, M., Biswas, S., and Sioutas, C.: Determination of particle effective density in urban environments with a differential mobility analyzer and aerosol particle mass analyzer, Aerosol Sci. Tech., 40, 709-723, https://doi.org/10.1080/02786820600803925, 2006.

Guan, W. J., Zheng, X. Y., Chung, K. F., and Zhong, N. S.: Impact of air pollution on the burden of chronic respiratory diseases in China: time for urgent action, Lancet, 388, 1939-1951, 2016.

Guo, S., Hu, M., Guo, Q., Zhang, X., Schauer, J. J., and Zhang, R.: Quantitative evaluation of emission controls on primary and secondary organic aerosol sources during Beijing 2008 Olympics, Atmos. Chem. Phys., 13, 8303-8314, https://doi.org/10.5194/acp-13-8303-2013, 2013.

Guo, S., Hu, M., Zamora, M. L., Peng, J., Shang, D., Zheng, J., Du, Z., Wu, Z., Shao, M., Zeng, L., Molina, M. J., and Zhang, R.: Elucidating severe urban haze formation in China, P. Natl. Acad. Sci. USA, 111, 17373-17378, https://doi.org/10.1073/pnas.1419604111, 2014.

Gysel, M., Crosier, J., Topping, D. O., Whitehead, J. D., Bower, K. N., Cubison, M. J., Williams, P. I., Flynn, M. J., McFiggans, G. B., and Coe, H.: Closure study between chemical composition and hygroscopic growth of aerosol particles during TORCH2, Atmos. Chem. Phys., 7, 6131-6144, https://doi.org/10.5194/acp7-6131-2007, 2007.

Gysel, M., McFiggans, G. B., and Coe, H.: Inversion of tandem differential mobility analyser (TDMA) measurements, J. Aerosol Sci., 40, 134-151, https://doi.org/10.1016/j.jaerosci.2008.07.013, 2009.

Han, B., Zhang, R., Yang, W., Bai, Z., Ma, Z., and Zhang, W.: Heavy haze episodes in Beijing during January 2013: Inorganic ion chemistry and source analysis using highly time-resolved measurements from an urban site, Sci. Total Environ., 544, 319-329, https://doi.org/10.1016/j.scitotenv.2015.10.053, 2016.

Heal, M. R., Kumar, P., and Harrison, R. M.: Particles, air quality, policy and health, Chem. Soc. Rev., 41, 6606-6630, https://doi.org/10.1039/c2cs35076a, 2012.

Hu, M., Peng, J., Sun, K., Yue, D., Guo, S., Wiedensohler, A., and $\mathrm{Wu}, \mathrm{Z}$.: Estimation of size-resolved ambient particle density based on the measurement of aerosol number, mass, and chemical size distributions in the winter in Beijing, Environ. Sci. Technol., 46, 9941-9947, https://doi.org/10.1021/es204073t, 2012.

Hu, Q. Q., Fu, H. B., Wang, Z. Z., Kong, L. D., Chen, M. D., and Chen, J. M.: The variation of characteristics of individual particles during the haze evolution in the urban Shanghai atmosphere, Atmos. Res., 181, 95-105, https://doi.org/10.1016/j.atmosres.2016.06.016, 2016.

Huang, R.-J., Zhang, Y., Bozzetti, C., Ho, K.-F., Cao, J.-J., Han, Y., Daellenbach, K. R., Slowik, J. G., Platt, S. M., Canonaco, F., Zotter, P., Wolf, R., Pieber, S. M., Bruns, E. A., Crippa, M., Ciarelli, G., Piazzalunga, A., Schwikowski, M., Abbaszade, G., Schnelle-Kreis, J., Zimmermann, R., An, Z., Szidat, S., Baltensperger, U., El Haddad, I., and Prevot, A. S. H.: High secondary aerosol contribution to particulate pollution during haze events in China, Nature, 514, 218-222, https://doi.org/10.1038/nature13774, 2014.

IPCC: Climate Change 2013: The Physical Science Basis, Cambridge, Contribution of Working Group I to the Fifth Assessment Report of the Intergovernmental Panel on Climate Change, UK, 2013.

Khalizov, A. F., Xue, H., Wang, L., Zheng, J., and Zhang, R.: Enhanced Light Absorption and Scattering by Carbon Soot Aerosol Internally Mixed with Sulfuric Acid, J. Phys. Chem. A, 113, 1066-1074, https://doi.org/10.1021/jp807531n, 2009.

Kulmala, M., Petaja, T., Nieminen, T., Sipila, M., Manninen, H. E., Lehtipalo, K., Dal Maso, M., Aalto, P. P., Junninen, H., Paasonen, P., Riipinen, I., Lehtinen, K. E., Laaksonen, A., and Kerminen, V. M.: Measurement of the nucleation of atmospheric aerosol particles, Nat. Protoc., 7, 1651-1667, https://doi.org/10.1038/nprot.2012.091, 2012

Levy, M. E., Zhang, R. Y., Khalizov, A. F., Zheng, J., Collins, D. R., Glen, C. R., Wang, Y., Yu, X. Y., Luke, W., Jayne, J. T., and Olaguer, E.: Measurements of submicron aerosols in Houston, Texas during the 2009 SHARP field campaign, J. Geophys. Res.- 
Atmos., 118, 10518-10534, https://doi.org/10.1002/jgrd.50785, 2013.

Levy, M. E., Zhang, R. Y., Zheng, J., Tan, H. B., Wang, Y., Molina, L. T., Takahama, S., Russell, L. M., and Li, G. H.: Measurements of submicron aerosols at the California-Mexico border during the Cal-Mex 2010 field campaign, Atmos. Environ., 88, 308-319, https://doi.org/10.1016/j.atmosenv.2013.08.062, 2014.

Li, J. J., Wang, G. H., Ren, Y. Q., Wang, J. Y., Wu, C., Han, Y. N., Zhang, L., Cheng, C. L., and Meng, J. J.: Identification of chemical compositions and sources of atmospheric aerosols in Xi' an, inland China during two types of haze events, Sci. Total Environ., 566, 230-237, https://doi.org/10.1016/j.scitotenv.2016.05.057, 2016.

Li, L., Huang, Z. X., Dong, J. G., Li, M., Gao, W., Nian, H. Q., Fu, Z., Zhang, G. H., Bi, X. H., Cheng, P., and Zhou, Z.: Real time bipolar time-of-flight mass spectrometer for analyzing single aerosol particles, Int. J. Mass Spectrom., 303, 118-124, https://doi.org/10.1016/j.ijms.2011.01.017, 2011.

Li, P., Yan, R., Yu, S., Wang, S., Liu, W., and Bao, H.: Reinstate regional transport of $\mathrm{PM}_{2.5}$ as a major cause of severe haze in Beijing, P. Natl. Acad. Sci. USA, 112, E2739-E2740, https://doi.org/10.1073/pnas.1502596112, 2015.

Lin, Y., Huang, K., Zhuang, G., Fu, J. S., Wang, Q., Liu, T., Deng, C., and Fu, Q.: A multi-year evolution of aerosol chemistry impacting visibility and haze formation over an Eastern Asia megacity, Shanghai, Atmos. Environ., 92, 76-86, https://doi.org/10.1016/j.atmosenv.2014.04.007, 2014.

Liu, H. J., Zhao, C. S., Nekat, B., Ma, N., Wiedensohler, A., van Pinxteren, D., Spindler, G., Müller, K., and Herrmann, H.: Aerosol hygroscopicity derived from size-segregated chemical composition and its parameterization in the North China Plain, Atmos. Chem. Phys., 14, 2525-2539, https://doi.org/10.5194/acp-14-2525-2014, 2014.

Malloy, Q. G. J., Nakao, S., Qi, L., Austin, R., Stothers, C., Hagino, H., and Cocker, D. R.: Real-Time Aerosol Density Determination Utilizing a Modified Scanning Mobility Particle SizerAerosol Particle Mass Analyzer System, Aerosol Sci. Tech., 43, 673-678, https://doi.org/10.1080/02786820902832960, 2009.

Massling, A., Stock, M., Wehner, B., Wu, Z. J., Hu, M., Bruggemann, E., Gnauk, T., Herrmann, H., and Wiedensohler, A.: Size segregated water uptake of the urban submicrometer aerosol in Beijing, Atmos. Environ., 43, 1578-1589, 2009.

Momenimovahed, A. and Olfert, J. S.: Effective density and volatility of particles emitted from gasoline direct injection vehicles and implications for particle mass measurement, Aerosol Sci. Tech., 49, 1051-1062, https://doi.org/10.1080/02786826.2015.1094181, 2015.

Niu, H. Y., Hu, W., Zhang, D. Z., Wu, Z. J., Guo, S., Pian, W., Cheng, W. J., and Hu, M.: Variations of fine particle physiochemical properties during a heavy haze episode in the winter of Beijing, Sci. Total Environ., 571, 103-109, https://doi.org/10.1016/j.scitotenv.2016.07.147, 2016.

Olfert, J. S., Symonds, J. P. R., and Collings, N.: The effective density and fractal dimension of particles emitted from a light-duty diesel vehicle with a diesel oxidation catalyst, J. Aerosol Sci., 38, 69-82, https://doi.org/10.1016/j.jaerosci.2006.10.002, 2007.

Pagels, J., Khalizov, A. F., McMurry, P. H., and Zhang, R. Y.: Processing of Soot by Controlled Sulphuric Acid and Water Conden-
sationMass and Mobility Relationship, Aerosol Sci. Tech., 43, 629-640, https://doi.org/10.1080/02786820902810685, 2009.

Park, K., Cao, F., Kittelson, D. B., and McMurry, P. H.: Relationship between particle mass and mobility for diesel exhaust particles, Environ. Sci. Technol., 37, 577-583, 2003.

Peng, J., Hu, M., Guo, S., Du, Z., Zheng, J., Shang, D., Zamora, M. L., Zeng, L., Shao, M., Wu, Y.-S., Zheng, J., Wang, Y., Glen, C. R., Collins, D. R., Molina, M. J., and Zhang, R.: Markedly enhanced absorption and direct radiative forcing of black carbon under polluted urban environments, P. Natl. Acad. Sci. USA, 113, 4266-4271, https://doi.org/10.1073/pnas.1602310113, 2016.

Petters, M. D. and Kreidenweis, S. M.: A single parameter representation of hygroscopic growth and cloud condensation nucleus activity, Atmos. Chem. Phys., 7, 1961-1971, https://doi.org/10.5194/acp-7-1961-2007, 2007.

Qiao, T., Zhao, M., Xiu, G., and Yu, J.: Simultaneous monitoring and compositions analysis of $\mathrm{PM}_{1}$ and $\mathrm{PM}_{2.5}$ in Shanghai: Implications for characterization of haze pollution and source apportionment, Sci. Total Environ., 557-558, 386-394, https://doi.org/10.1016/j.scitotenv.2016.03.095, 2016.

Rissler, J., Nordin, E. Z., Eriksson, A. C., Nilsson, P. T., Frosch, M., Sporre, M. K., Wierzbicka, A., Svenningsson, B., Londahl, J., Messing, M. E., Sjogren, S., Hemmingsen, J. G., Loft, S., Pagels, J. H., and Swietlicki, E.: Effective density and mixing state of aerosol particles in a near-traffic urban environment, Environ. Sci. Technol., 48, 6300-6308, https://doi.org/10.1021/es5000353, 2014.

Shi, Y., Chen, J., Hu, D., Wang, L., Yang, X., and Wang, X.: Airborne submicron particulate $\left(\mathrm{PM}_{1}\right)$ pollution in Shanghai, China: Chemical variability, formation/dissociation of associated semi-volatile components and the impacts on visibility, Sci. Total Environ., 473, 199-206, https://doi.org/10.1016/j.scitotenv.2013.12.024, 2014.

Spencer, M. T., Shields, L. G., and Prather, K. A.: Simultaneous measurement of the effective density and chemical composition of ambient aerosol particles, Environ. Sci. Technol., 41, 13031309, https://doi.org/10.1021/es061425+, 2007.

Sun, Y. L., Chen, C., Zhang, Y. J., Xu, W. Q., Zhou, L. B., Cheng, X. L., Zheng, H. T., Ji, D. S., Li, J., Tang, X., Fu, P. Q., and Wang, Z. F.: Rapid formation and evolution of an extreme haze episode in Northern China during winter 2015, Scientific Reports, 6, 27151, https://doi.org/10.1038/srep27151, 2016.

Swietlicki, E., Hansson, H. C., Hameri, K., Svenningsson, B., Massling, A., McFiggans, G., McMurry, P. H., Petaja, T., Tunved, P., Gysel, M., Topping, D., Weingartner, E., Baltensperger, U., Rissler, J., Wiedensohler, A., and Kulmala, M.: Hygroscopic properties of submicrometer atmospheric aerosol particles measured with H-TDMA instruments in various environments - a review, Tellus B, 60, 432-469, https://doi.org/10.1111/j.16000889.2008.00350.x, 2008.

Tao, Y., Ye, X. N., Ma, Z., Xie, Y. Y., Wang, R. Y., Chen, J. M., Yang, X., and Jiang, S. Q.: Insights into different nitrate formation mechanisms from seasonal variations of secondary inorganic aerosols in Shanghai, Atmos. Environ., 145, 1-9, https://doi.org/10.1016/j.atmosenv.2016.09.012, 2016.

Topping, D. O., McFiggans, G. B., and Coe, H.: A curved multicomponent aerosol hygroscopicity model framework: Part 1 - Inorganic compounds, Atmos. Chem. Phys., 5, 1205-1222, https://doi.org/10.5194/acp-5-1205-2005, 2005. 
Turpin, B. J. and Lim, H. J.: Species contributions to $\mathrm{PM}_{2.5}$ mass concentrations: Revisiting common assumptions for estimating organic mass, Aerosol Sci. Tech., 35, 602-610, https://doi.org/10.1080/02786820152051454, 2001

Wang, G., Zhang, R., Gomez, M. E., Yang, L., Zamora, M. L., Hu, M., Lin, Y., Peng, J., Guo, S., Meng, J., Li, J., Cheng, C., Hu, T., Ren, Y., Wang, Y., Gao, J., Cao, J., An, Z., Zhou, W., Li, G., Wang, J., Tian, P., Marrero-Ortiz, W., Secrest, J., Du, Z., Zheng, J., Shang, D., Zeng, L., Shao, M., Wang, W., Huang, Y., Wang, Y., Zhu, Y., Li, Y., Hu, J., Pan, B., Cai, L., Cheng, Y., Ji, Y., Zhang, F., Rosenfeld, D., Liss, P. S., Duce, R. A., Kolb, C. E., and Molina, M. J.: Persistent sulfate formation from London Fog to Chinese haze, P. Natl. Acad. Sci. USA, 113, 13630-13635, https://doi.org/10.1073/pnas.1616540113, 2016.

Wang, H., Xu, J., Zhang, M., Yang, Y., Shen, X., Wang, Y., Chen, D., and Guo, J.: A study of the meteorological causes of a prolonged and severe haze episode in January 2013 over central-eastern China, Atmos. Environ., 98, 146-157, https://doi.org/10.1016/j.atmosenv.2014.08.053, 2014.

Wang, Y., Wan, Q., Meng, W., Liao, F., Tan, H., and Zhang, R.: Long-term impacts of aerosols on precipitation and lightning over the Pearl River Delta megacity area in China, Atmos. Chem. Phys., 11, 12421-12436, https://doi.org/10.5194/acp-11-124212011, 2011.

Wang, Y., Khalizov, A., Levy, M., and Zhang, R.: New Directions: Light absorbing aerosols and their atmospheric impacts, Atmos. Environ., 81, 713-715, https://doi.org/10.1016/j.atmosenv.2013.09.034, 2013.

Wang, Y., Zhang, Q., Jiang, J., Zhou, W., Wang, B., He, K., Duan, F., Zhang, Q., Philip, S., and Xie, Y.: Enhanced sulfate formation during China's severe winter haze episode in January 2013 missing from current models, J. Geophys. Res.-Atmos., 119, 1042510440, https://doi.org/10.1002/2013jd021426, 2014a.

Wang, Y., Zhang, R., and Saravanan, R.: Asian pollution climatically modulates mid-latitude cyclones following hierarchical modelling and observational analysis, Nat. Commun., 5, 3098, https://doi.org/10.1038/ncomms4098, 2014b.

Wang, Y. H., Liu, Z. R., Zhang, J. K., Hu, B., Ji, D. S., Yu, Y. C., and Wang, Y. S.: Aerosol physicochemical properties and implications for visibility during an intense haze episode during winter in Beijing, Atmos. Chem. Phys., 15, 3205-3215, https://doi.org/10.5194/acp-15-3205-2015, 2015.

Wu, G., Li, Z., Fu, C., Zhang, X., Zhang, R., Zhang, R., Zhou, T., Li, J., Li, J., Zhou, D., Wu, L., Zhou, L., He, B., and Huang, R.: Advances in studying interactions between aerosols and monsoon in China, Science China-Earth Sciences, 59, 1-16, https://doi.org/10.1007/s11430-015-5198-z, 2016.

Wu, S., Ni, Y., Li, H., Pan, L., Yang, D., Baccarelli, A. A., Deng, F., Chen, Y., Shima, M., and Guo, X.: Short-term exposure to high ambient air pollution increases airway inflammation and respiratory symptoms in chronic obstructive pulmonary disease patients in Beijing, China, Environ. Int., 94, 7682, https://doi.org/10.1016/j.envint.2016.05.004, 2016.

Wu, Z. J., Zheng, J., Shang, D. J., Du, Z. F., Wu, Y. S., Zeng, L. M., Wiedensohler, A., and Hu, M.: Particle hygroscopicity and its link to chemical composition in the urban atmosphere of Beijing, China, during summertime, Atmos. Chem. Phys., 16, 1123 1138, https://doi.org/10.5194/acp-16-1123-2016, 2016.
Xiao, S., Wang, Q. Y., Cao, J. J., Huang, R. J., Chen, W. D., Han, Y. M., Xu, H. M., Liu, S. X., Zhou, Y. Q., Wang, P., Zhang, J. Q., and Zhan, C. L.: Long-term trends in visibility and impacts of aerosol composition on visibility impairment in Baoji, China, Atmos. Res., 149, 88-95, https://doi.org/10.1016/j.atmosres.2014.06.006, 2014.

Xiao, S., Wang, M. Y., Yao, L., Kulmala, M., Zhou, B., Yang, X., Chen, J. M., Wang, D. F., Fu, Q. Y., Worsnop, D. R., and Wang, L.: Strong atmospheric new particle formation in winter in urban Shanghai, China, Atmos. Chem. Phys., 15, 1769-1781, https://doi.org/10.5194/acp-15-1769-2015, 2015.

Xie, Y., Ding, A., Nie, W., Mao, H., Qi, X., Huang, X., Xu, Z., Kerminen, V.-M., Petaja, T., Chi, X., Virkkula, A., Boy, M., Xue, L., Guo, J., Sun, J., Yang, X., Kulmala, M., and Fu, C.: Enhanced sulfate formation by nitrogen dioxide: Implications from in situ observations at the SORPES station, J. Geophys. Res.-Atmos., 120, 12679-12694, https://doi.org/10.1002/2015jd023607, 2015.

Yang, L., Zhou, X., Wang, Z., Zhou, Y., Cheng, S., Xu, P., Gao, X., Nie, W., Wang, X., and Wang, W.: Airborne fine particulate pollution in Jinan, China: Concentrations, chemical compositions and influence on visibility impairment, Atmos. Environ., 55, 506-514, https://doi.org/10.1016/j.atmosenv.2012.02.029, 2012.

Ye, X. N., Chen, T. Y., Hu, D. W., Yang, X., Chen, J. M., Zhang, R. Y., Khakuziv, A. F., and Wang, L.: A multifunctional HTDMA system with a robust temperature control, Adv. Atmos. Sci., 26, 1235-1240, https://doi.org/10.1007/s00376-009-8134-3, 2009.

Ye, X. N., Ma, Z., Hu, D. W., Yang, X., and Chen, J. M.: Sizeresolved hygroscopicity of submicrometer urban aerosols in Shanghai during wintertime, Atmos. Res., 99, 353-364, 2010.

Ye, X. N., Ma, Z., Zhang, J. C., Du, H. H., Chen, J. M., Chen, H., Yang, X., Gao, W., and Geng, F. H.: Important role of ammonia on haze formation in Shanghai, Environ. Res. Lett., 6, 024019, https://doi.org/10.1088/1748-9326/6/2/024019, 2011.

Ye, X. N., Tang, C., Yin, Z., Chen, J. M., Ma, Z., Kong, L. D., Yang, X., Gao, W., and Geng, F. H.: Hygroscopic growth of urban aerosol particles during the 2009 Mirage-Shanghai Campaign, Atmos. Environ., 64, 263-269, https://doi.org/10.1016/j.atmosenv.2012.09.064, 2013.

Yin, Z., Ye, X., Jiang, S., Tao, Y., Shi, Y., Yang, X., and Chen, J.: Size-resolved effective density of urban aerosols in Shanghai, Atmos. Environ., 100, 133-140, https://doi.org/10.1016/j.atmosenv.2014.10.055, 2015.

Zhang, Q., Quan, J., Tie, X., Li, X., Liu, Q., Gao, Y., and Zhao, D.: Effects of meteorology and secondary particle formation on visibility during heavy haze events in Beijing, China, Sci. Total Environ., 502, 578-584, https://doi.org/10.1016/j.scitotenv.2014.09.079, 2015.

Zhang, R., Khalizov, A., Wang, L., Hu, M., and Xu, W.: Nucleation and Growth of Nanoparticles in the Atmosphere, Chem. Rev., 112, 1957-2011, https://doi.org/10.1021/cr2001756, 2012.

Zhang, R., Guo, S., Zamora, M. L., and Hu, M.: Reply to Li et al.: Insufficient evidence for the contribution of regional transport to severe haze formation in Beijing, P. Natl. Acad. Sci. USA, 112, E2741-E2741, https://doi.org/10.1073/pnas.1503855112, 2015a.

Zhang, R., Wang, G., Guo, S., Zarnora, M. L., Ying, Q., Lin, Y., Wang, W., Hu, M., and Wang, Y.: Formation of Ur- 
ban Fine Particulate Matter, Chem. Rev., 115, 3803-3855, https://doi.org/10.1021/acs.chemrev.5b00067, 2015 b.

Zhang, R. Y., Suh, I., Zhao, J., Zhang, D., Fortner, E. C., Tie, X. X., Molina, L. T., and Molina, M. J.: Atmospheric new particle formation enhanced by organic acids, Science, 304, 1487-1490, https://doi.org/10.1126/science.1095139, 2004.

Zhang, R. Y., Khalizov, A. F., Pagels, J., Zhang, D., Xue, H. X., and McMurry, P. H.: Variability in morphology, hygroscopicity, and optical properties of soot aerosols during atmospheric processing, P. Natl. Acad. Sci. USA, 105, 10291-10296, 2008.

Zhao, J., Khalizov, A., Zhang, R., and McGraw, R.: HydrogenBonding Interaction in Molecular Complexes and Clusters of Aerosol Nucleation Precursors, J. Phys. Chem. A, 113, 680-689, https://doi.org/10.1021/jp806693r, 2009.
Zhao, X. J., Zhao, P. S., Xu, J., Meng,, W., Pu, W. W., Dong, F., He, D., and Shi, Q. F.: Analysis of a winter regional haze event and its formation mechanism in the North China Plain, Atmos. Chem. Phys., 13, 5685-5696, https://doi.org/10.5194/acp13-5685-2013, 2013.

Zheng, G. J., Duan, F. K., Su, H., Ma, Y. L., Cheng, Y., Zheng, B., Zhang, Q., Huang, T., Kimoto, T., Chang, D., Pöschl, U., Cheng, Y. F., and He, K. B.: Exploring the severe winter haze in Beijing: the impact of synoptic weather, regional transport and heterogeneous reactions, Atmos. Chem. Phys., 15, 2969-2983, https://doi.org/10.5194/acp-15-2969-2015, 2015. 